\title{
ST-segment elevation myocardial infarction with cardiogenic shock: from bad to worse
}

\section{Zoran Miovski*, Joško Bulum, Hrvoje Jurin}

University of Zagreb School of Medicine, University Hospital Centre Zagreb, Zagreb, Croatia
RECEIVED:

February 9, 2016

ACCEPTED:

February 20, 2016

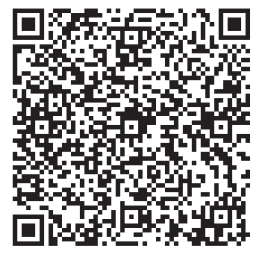

KEYWORDS: ST-segment elevation myocardial infarction, T-stenting and small protrusion technique, cardiogenic shock.

CITATION: Cardiol Croat. 2016;11(3-4):103. | DOI: http://dx.doi.org/10.15836/ccar2016.103

*ADDRESS FOR CORRESPONDENCE: Zoran Miovski, Klinički bolnički centar Zagreb, Kišpatićeva 12, HR-10000 Zagreb, Croatia. / Phone: +385-98-464-811 / E-mail: miovski.zoran@gmail.com

ORCID: Zoran Miovski, http://orcid.org/0000-0002-3850-8905 • Joško Bulum, http://orcid.org/0000-0002-1482-6503 Hrvoje Jurin, http://orcid.org/0000-0002-2599-553X

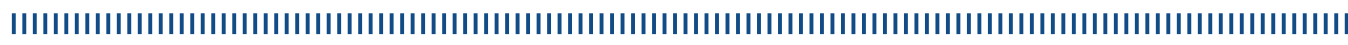

Introduction: Cardiogenic shock is the most common cause of fatal outcomes in catheterization laboratories. It is also the most challenging state. In this report we present an interesting case of cardiogenic shock in younger patient.

Case report: 49-year-old male was referred from a local hospital to University Hospital Centre Zagreb because of chest pain and ST-segment elevation. At presentation the patient had high blood pressure (RR 220/100 mmHg), was agitated and pail. In the local hospital he received the loading dose of ticagrelor and aspirin. At arrival to the catheterization laboratory, patient was disoriented, with brachial blood pressure of $80 / 40 \mathrm{mmHg}$, had dyspnea with low peripheral oxygen saturation of $80 \%$, and pulmonary edema. At auscultation the patient had no precordial murmurs which suggested an acute mitral regurgitation. He was then intubated and mechanical ventilation was started. Due to the lack of radial pulses, we proceeded with right transfemoral approach. Short after sheet insertion, the patient went to cardiopulmonary arrest due to the pulseless electrical activity. Prolonged cardiopulmonary resuscitation was performed, and multiple defibrillations were made due to ventricular fibrillations. After 20 min of resuscitation, spontaneous circulation was obtained. Coronary angiography showed thrombotic occlusion of proximal left anterior descending coronary artery (LAD), without collaterals, marginal stenosis of proximal left circumflex artery (LCX) and normal right coronary artery (RCA). During that time patient was extremely hemodynamically unstable with maximal parenteral inotropic therapy (invasive blood pressure of $60 / 30 \mathrm{mmHg}$ ) and repetitive ventricular fibrillations. Patient was then referred to the extracorporeal membrane oxygenation team. Complex bifurcation percutaneous coronary intervention with 2 drug-eluting stents was performed (T-stenting and small protrusion technique - LAD/LCX), that resulted in partial hemodynamic (RR 90/50 $\mathrm{mmHg}$ ) and rhythmologic stabilization. The pressure on the femoral sheet showed normal systolic and low diastolic pressure (RR 140/50 mmHg), suggesting severe aortic valve regurgitation, and possible aortic dissection. Aortography confirmed DeBakey type I aortic dissection. The patient was referred to a cardiac surgeon, and an urgent operation was indicated. Shortly after, during CT scan, patient went to cardiopulmonary arrest due to occlusion of the RCA and aortic rupture that resulted with cardiac tamponade and death.

Conclusion: Acute aortic dissection in frequently misdiagnosed as acute coronary syndrome. Acute coronary syndrome has diagnostic advantages in rapid laboratory tests and ECG. For aortic dissection there are no equivalent rapid diagnostic tests. Unfortunately tests for acute coronary syndrome can be misleading. It is of the most importance to follow small details, that can lead to faster diagnosis and treatment. In patient with Stanford A dissection and cardiogenic shock as a result of occlusion of left main coronary artery, PCI can be bridge to surgery ${ }^{1}$.

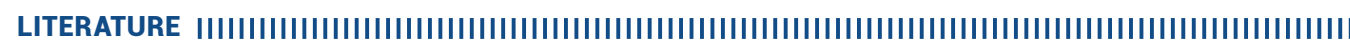

1. Barabas $M$, Gosselin G, Crépeau J, Petitclerc R, Cartier R, Théroux P. Left main stenting-as a bridge to surgery-for acute type A aortic dissection and anterior myocardial infarction. Catheter Cardiovasc Interv. 2000;51(1):74-7. Dol: http://dx.doi.org/10.1002/1522-726X(200009)51:1744:AID-CCD17>3.0.C0;2-F 